\title{
0culo-auriculo-vertebral spectrum with radial defects, a bifid condyle and taurodontism: A case report
}

\section{Spektrum objawów oczno-uszno-kręgowych z wadami promieniowymi, dwudzielnym kłykciem i taurodontyzmem - opis przypadku}

\author{
Vela Desai ${ }^{\mathrm{D}-\mathrm{F}}$ \\ Jaipur Dental College, India \\ A - research concept and design; B - collection and/or assembly of data; $C$ - data analysis and interpretation; \\ $D$ - writing the article; $E$ - critical revision of the article; $F$ - final approval of the article
}

\section{Address for correspondence \\ Vela Desai \\ E-mail: drveladesai@hotmail.com}

\section{Funding sources}

None declared

Conflict of interest

None declared

Received on April 23, 2019

Reviewed on May 23, 2019

Accepted on June 24, 2019

Published online on November 5, 2019

Cite as

Desai V. Oculo-auriculo-vertebral spectrum with radial defects, a bifid condyle and taurodontism: A case report. Dent Med Probl. 2019;56(4):427-431. doi:10.17219/dmp/110234

D0I

$10.17219 / \mathrm{dmp} / 110234$

Copyright

๑ 2019 by Wroclaw Medical University

This is an article distributed under the terms of the

Creative Commons Attribution 3.0 Unported License (CC BY 3.0)

(https://creativecommons.org/licenses/by/3.0/)

\begin{abstract}
Goldenhar syndrome (GS) is a rare congenital anomaly involving the first and second branchial arches. It is an autosomal dominant genetic disorder in which there is abnormal prenatal development of the head and face leading to the subsequent asymmetry of craniofacial structures. It is generally sporadic, with its incidence ranging from 1:3,500 to 1:5,600 live births and a gender ratio of 3:2 (male:female). Goldenhar syndrome is considered to be a variant of hemifacial microsomia, characterized additionally by vertebral anomalies and epibulbar dermoids. Facio-auricular dysplasias represent a single disorder with great variability of expression, and an isolated ear malformation may represent the mildest expression of the disorder.

This report presents a case of the oculo-auriculo-vertebral spectrum (OAVS) with radial defects, a unilateral bifid condyle and taurodontism. The presence of a bifid condyle and taurodontism has not been previously reported in the literature. Whether this is a coincidental or new finding has to be hypothesized and confirmed. The documentation of all such new findings is of utmost importance for updating the existing literature.
\end{abstract}

Key words: hypoplasia, bifid condyle, hemifacial microsomia, Goldenhar syndrome, taurodontism

Słowa kluczowe: hipoplazja, dwudzielny kłykieć, mikrosomia połowy twarzy, zespół Goldenhara, taurodontyzm 


\section{Introduction}

In 1861, Goldenhar syndrome (GS) was first observed by Canton, and later in 1881 by an Austrian physician Ferdinand von Arlt; however, it went unnoticed. ${ }^{1}$ In 1952, Maurice Goldenhar, a Belgian-American ophthalmologist, described the syndrome in detail as Goldenhar syndrome. ${ }^{2}$ In 1963, Robert James Gorlin described this syndrome with vertebral anomalies. ${ }^{3}$ It is also known as oculo-auriculo-vertebral (OAV) syndrome, hemifacial microsomia, first arch syndrome, first and second branchial arch syndrome, Goldenhar-Gorlin syndrome, lateral facial dysplasia, unilateral craniofacial microsomia, otomandibular dysostosis, unilateral intrauterine facial necrosis, and auriculo-branchiogenic dysplasia. ${ }^{4-6}$ Very few cases with a radial defect are documented in the literature along with various other findings. ${ }^{7,8}$ In this report, the author illustrated another case of the oculo-auriculo-vertebral spectrum (OAVS) with radial defects, along with an interesting finding of a bifid condyle and taurodontism.

\section{Case report}

An 18-year-old female patient visited the Department of Oral Medicine and Radiology at Jaipur Dental College, India, with a complaint of sensitivity in the lower anterior teeth in the preceding 6 months. Her medical history revealed that she had consulted various physicians in her childhood for unilateral hearing loss and the upper left limb defect below the elbow. No investigations were conducted and the patient did not carry any records. Due to the poor financial status, the family had not sought any treatment. She was born of a full-term normal delivery at home. There was no history of maternal illness during pregnancy. All other family members were normal. She was born of a non-consanguineous marriage and all milestones were reported as normal. She was afebrile, with normal pulse rate, blood pressure and respiratory rate. The physical examination revealed a well-nourished 18-year-old, ambulating well, without limp or support. The lower extremity and neurovascular examination showed no abnormalities. An altered posture was evident, as the head was not centered in the mid-sagittal plane with a prominent sternoocleidomastoid muscle on the left (Fig. 1). Her upper left limb showed a radial defect. There was radius hypoplasia and thumb agenesis (Fig. 2). A deformed left ear and ear tags were evident (Fig. 3), which could be classified as thirddegree microtia according to Weerda. The patient reported partial hearing on the same side. Ocular changes were manifested with a whitish covering of the sclera in the left eye (epibulbar dermoids) and diminished vision (Fig. 1). Speech was not clear, as she also presented with partial ankyloglossia.

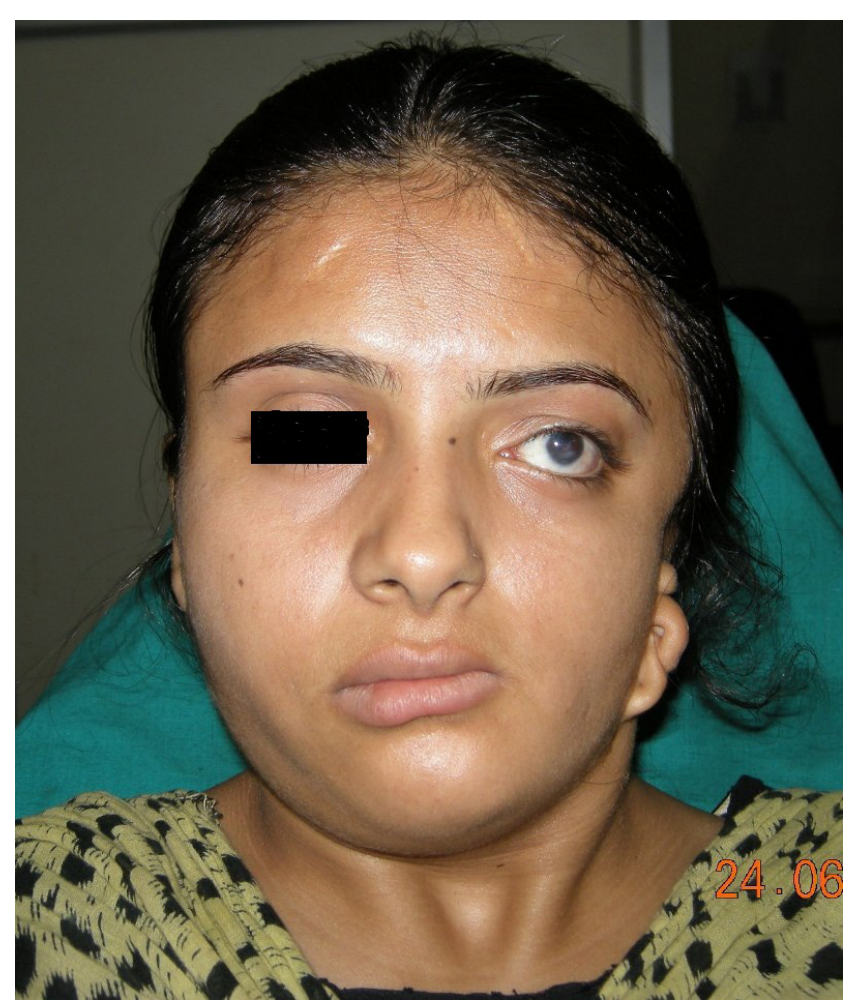

Fig. 1. 18-year-old female patient with an asymmetrical face and epibulbar dermoids on the left side

An additional oral examination showed facial asymmetry with hemifacial hypoplasia, limited mouth opening and a deviation of the mandible to the right on opening the mouth (Fig. 4). The intraoral examination revealed the crowding of the anterior teeth, a deep bite and generalized recession suggestive of chronic periodontitis (Fig. 5). Orthopantomography (OPG) revealed a hypoplastic left body of the mandible (evident as a reduced height and width of the body), ramus (a reduced height and width of the ramus compared to the right side) and condyle (Fig. 6). A prominent antegonial angle and a bifid condyle on the left (heart-shaped condylar head), missing upper third molars,

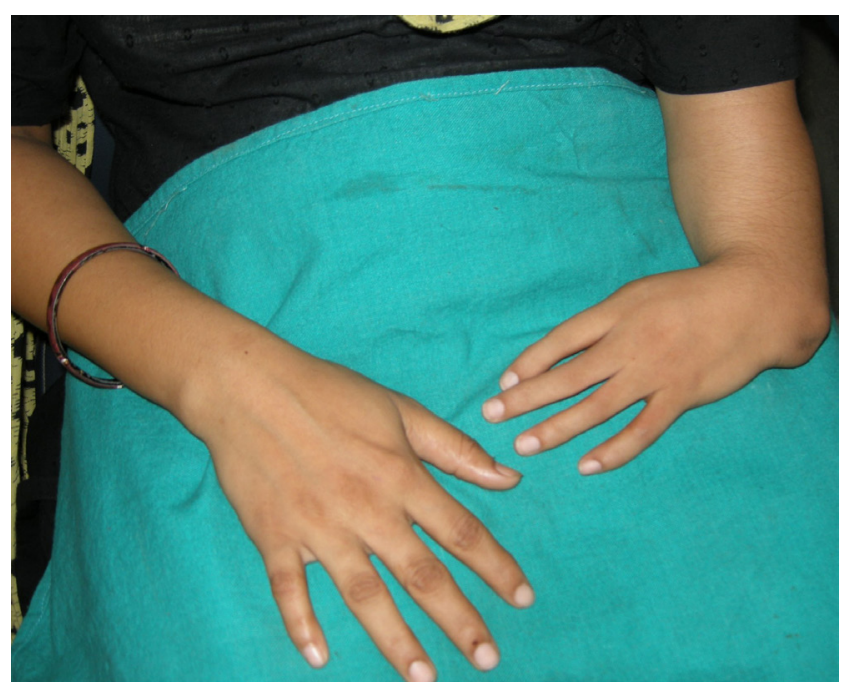

Fig. 2. Radial defect with only 4 fingers 


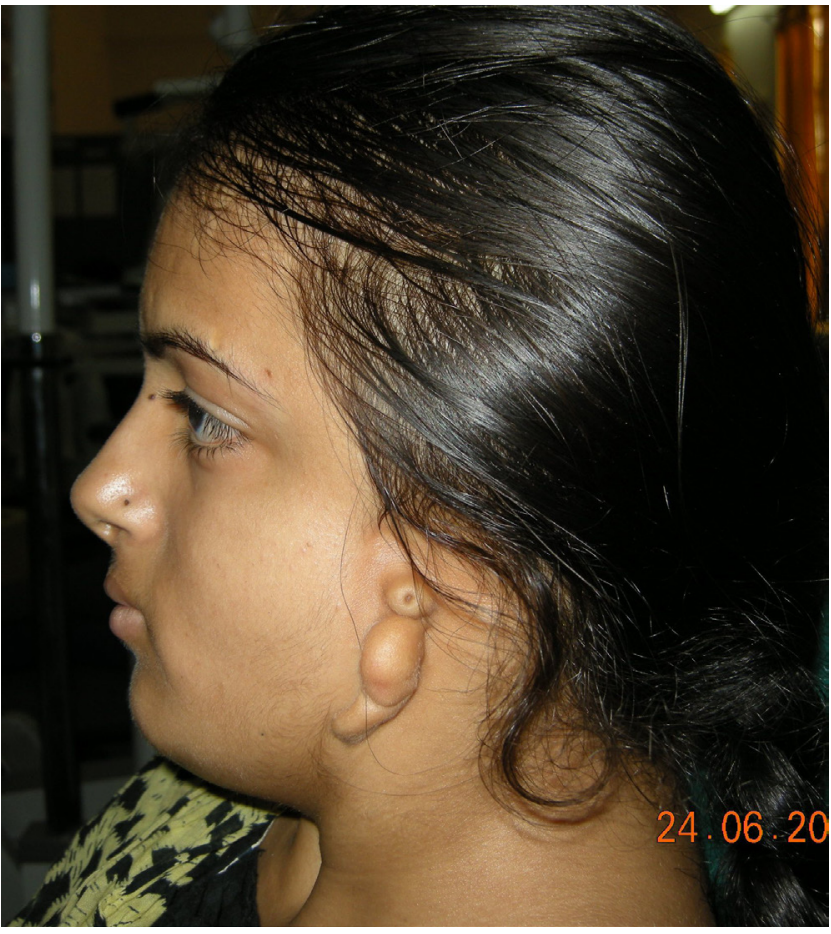

Fig. 3. Deformed left ear with ear tags

and impacted lower third molar taurodontism with teeth 37 and 47 were visualized. An underdeveloped orbit, maxilla and hard palate on the left side were noticed. Generalized alveolar bone loss was also evident. An intraoral periapical radiograph of the $3^{\text {rd }}$ quadrant clearly depicts hypotaurodontism with tooth 37 (Fig. 7). A diagnosis of OAVS with radial defects, a bifid condyle and taurodontism was suggested. The patient was referred for thorough evaluation to rule out other systemic involvement, as she required a multidisciplinary approach and would be treated accordingly.

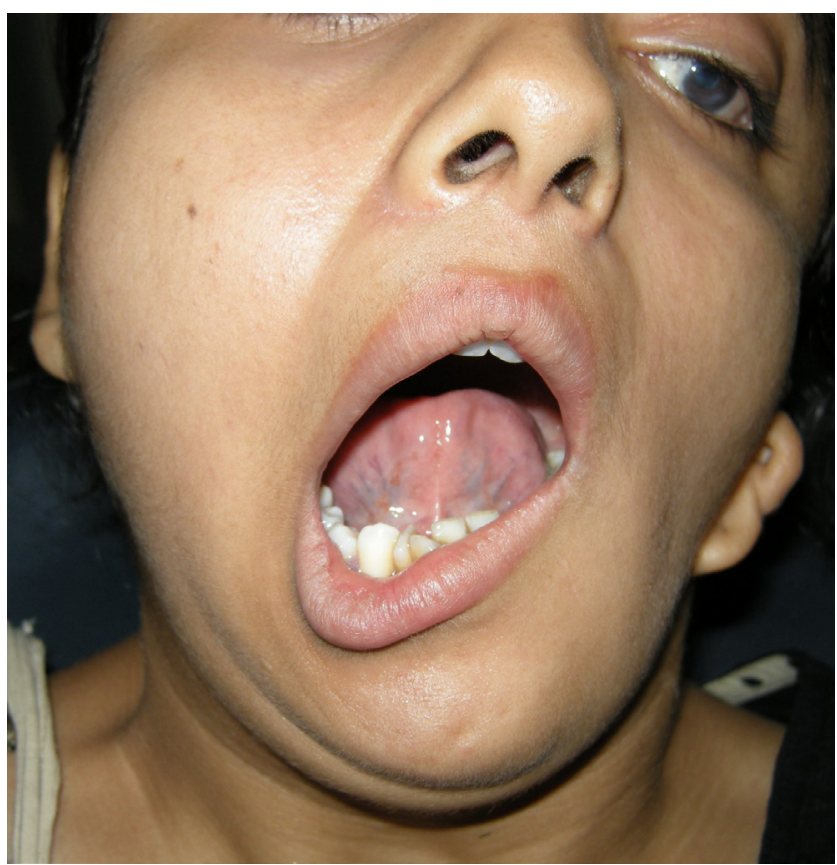

Fig. 4. Deviation of the mandible on mouth opening

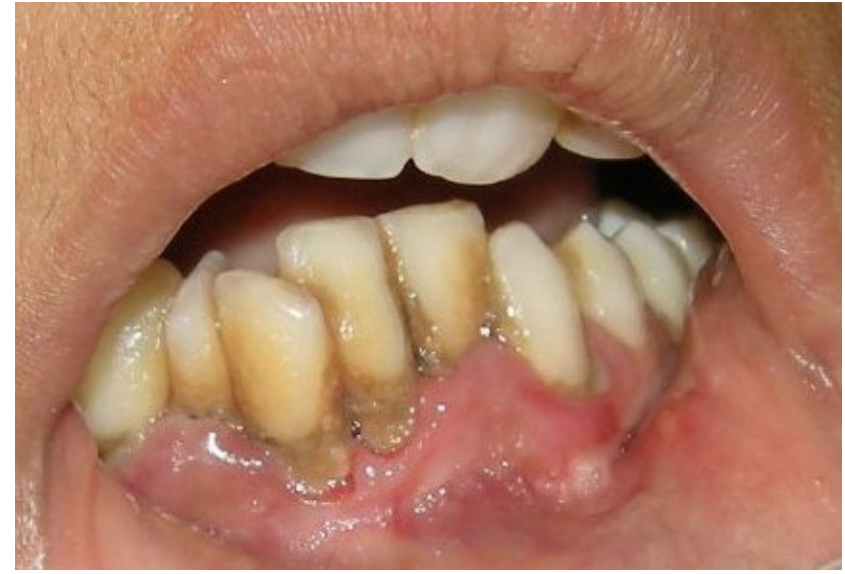

Fig. 5. Intraoral view showing the crowding of the lower anterior teeth and gingival recession

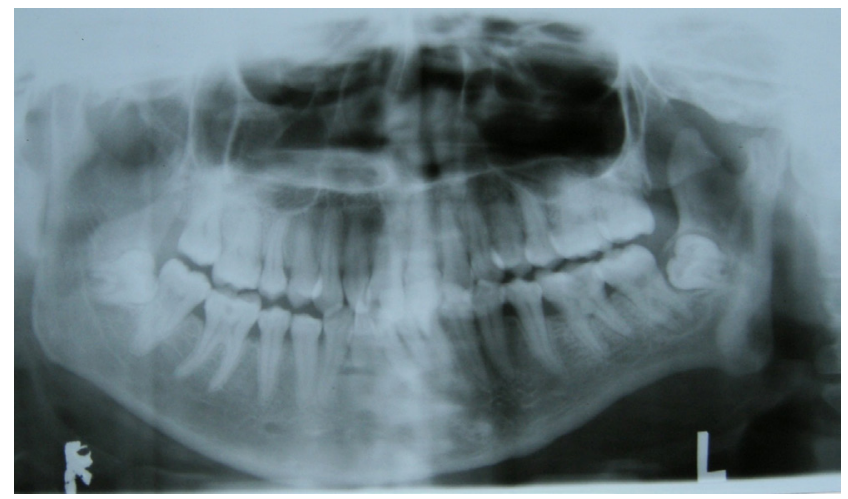

Fig. 6. Orthopantomography (OPG) revealing a hypoplastic mandible on the left side with a bifid condyle

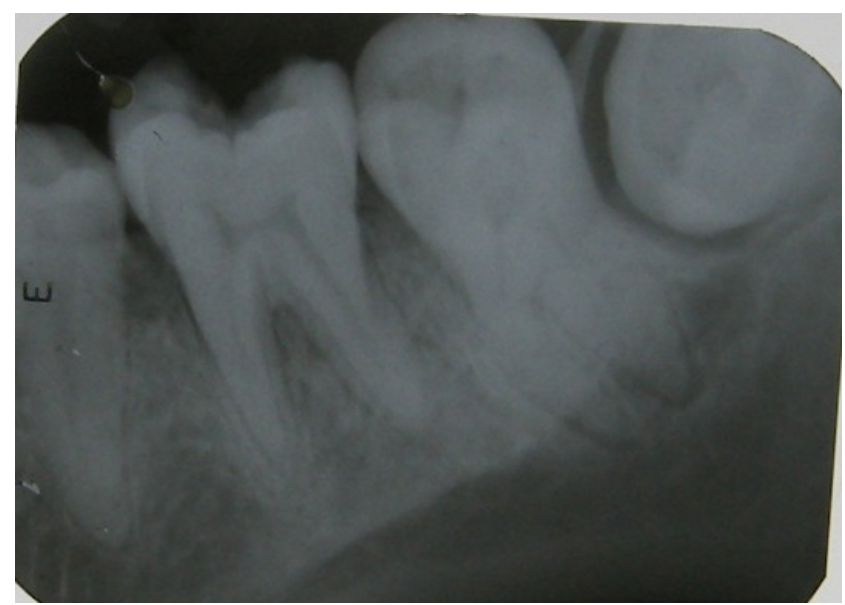

Fig. 7. Intraoral periapical radiograph showing taurodontism with tooth 37

\section{Discussion}

The oculo-auriculo-vertebral spectrum or GS is a wellrecognized condition characterized by variable degrees of unilateral or bilateral involvement of craniofacial structures, including the first and second branchial arches, ocular anomalies and vertebral defects. In the present case, 
a bifid condyle and taurodontism along with radial defects are presented, which has so far not been recorded in the literature in English.

Some authors suggested that GS might result from the interaction of many genes, possibly in combination with the environmental factors; others pointed to a possible link between genetic causes and vascular disruption, e.g., due to a fetal hemorrhage in the first and second branchial arches at the time when blood supply switches from the stapedial artery to the external carotid artery. Furthermore, disturbances in the development of the neural crest were indicated as possible reasons of this syndrome. The ingestion of drugs such as thalidomide, retinoic acid, tamoxifen, and cocaine by pregnant woman may be a risk factor as well. The pathogenetic mechanisms have been discussed theoretically and are a matter of controversy, but so far, no definitive causal agent has been confirmed. It has been postulated that GS represents a defect of blastogenesis that could be attributed to the interferences in cephalic neural crest cell migration; however, in some cases of OAVS with multisystemic malformations, the involvement of several developmental fields does not sustain localized damage. ${ }^{8-12}$

Clinically, it ranges from isolated microtia, with or without mandibular hypoplasia, to a more complex phenotype with skeletal, cardiac, renal, pulmonary, and central nervous system (CNS) manifestations. The oculo-auriculovertebral spectrum with radial defects is a subset within OAVS, mainly involving unilaterally or bilaterally the first branchial arches and limb primordium. The main signs include external, middle and internal ear malformations, facial asymmetry, orofacial clefts, mandibular hypoplasia, and a radial defect, which is a 'sine qua non' anomaly for the clinical diagnosis. ${ }^{8}$ In the case presented, all of the signs were noticed, except for orofacial clefts. There was a bifid condyle and taurodontism with the lower left second molar, which has so far not been reported.

Due to the delay in growth and development, the effects of the syndrome appear more evident as the child grows, mainly as craniofacial microsomia. It is diagnosed clinically, but requires complementary evaluation that includes a hematological and hormonal study depending on the presentation as well as chromosome studies. An audiological investigation comprises pure tone audiometry, speech audiometry, tympanometry, stapedius reflex measurement, and brainstem auditory evoked response. Two-dimensional (2D) echocardiography for cardiac abnormalities, skull, facial, upper limb, and spine X-rays, temporal bone computed tomography $(\mathrm{CT})$, spine $\mathrm{CT}$, and magnetic resonance imaging (MRI) are also performed, if required.

The treatment depends on the patient's age and systemic manifestations, but generally requires a multidisciplinary approach. ${ }^{13-20}$ In order to correct a craniofacial malformation, a team consisting of a maxillofacial and plastic surgeon, orthodontist, speech therapist, etc. is required, along with a pediatrician, ophthalmologist, cardiologist, otolaryngologist, and genetic counselor.

At birth, the functional concerns in OAVS are the patency and adequacy of the airway, swallowing and feeding, hearing, vision, and the presence of other malformations that may have systemic implications.

Airway and oxygenation monitoring are essential. Airway problems can be treated by infant positioning, nasopharyngeal airway placement, tongue-lip adhesion, distraction osteogenesis to advance the mandible, or tracheotomy. Feeding difficulties are managed with nasogastric tube feeding or the placement of a gastrostomy tube to maintain a positive nitrogen balance while allowing sufficient oxygenation.

The aim of the treatment is to achieve better functioning and an esthetically pleasing outcome, allowing the patient to lead a normal life as much as possible. With the continued growth of the child, the effects of GS may become more pronounced, since the affected areas will show a significant delay in development. This can result in cosmetic concerns, breathing difficulties and malocclusion. The timing of primary and secondary reconstructions plays an important role in the complex treatment. Primary reconstruction consists of cleft repair, the corrections of colobomas and ear deformities, and the extirpation of dermoids and preauricular tags. Between years 2 and 4, no treatment is indicated for patients who are mildly affected. Reconstruction by a rib bone graft and the lengthening of the underdeveloped mandible with a bone distraction device is recommended in the case of a severely underdeveloped mandible, and modifications in the growth of teeth are made with the assistance of orthodontics. Orthodontic therapy may be started with removable appliances. With the appearance of permanent dentition, fixed orthodontic therapy can be initiated to create a proper occlusal plane, and to correct malocclusion and tooth discrepancies. The reconstruction of the external ear is performed in several stages over a period of 6-12 months between years 6 and 8 , and the structural anomalies of the eye and ear can be corrected by means of plastic surgery. At the age of 8-10 years, the asymmetry of the cheeks is to be corrected. This may be the most important stage in the entire treatment program, in terms of physical appearance. Jaw surgery is carried out at or close to skeletal maturity, whereby in the case of mild involvement, no surgery is required. The extent of the temporomandibular joint (TMJ) dysmorphology is a principal factor when considering the timing of and techniques for mandibular reconstruction. Surgical correction includes costochondral rib grafts with osteotomy and distraction procedures.

Children with GS usually have reduced oral opening and/or malocclusion, and hence oral hygiene is more difficult, which exposes them to an increased risk of both dental caries and gingivitis. Toothbrushes with smaller heads and waterjet systems can be recommended to patients 
with limited mouth opening to improve the mechanical removal of plaque. Regular dental visits that include topical fluoride application, with an emphasis on the prevention of future disease, should be an important consideration in these individuals, especially in the cases like the present one because of the disability of the limbs. ${ }^{21}$

The literature reveals that OAVS and radial defects have been reported in mothers with a history of diabetes and shows that pregnant women with pre-existing or gestational diabetes are at a higher risk of giving birth to a child with malformations. Therefore, special attention should be paid to maternal glycemia as a precautionary measure. ${ }^{8}$

\section{Conclusions}

As OAVS subjects with radial defects are more frequently affected with cardiovascular defects, thorough systemic evaluation is mandatory for better quality of life and better prognosis. This case was a classical one with newer findings, and as such, it should be regarded as a contribution to the description of numerous GS features, updating the literature and knowledge.

\section{ORCID iDs}

Vela Desai (1) https://orcid.org/0000-0001-9926-5364

\section{References}

1. von Arlt F. Clinical Presentation of Diseases of the Eye [in German]. $1^{\text {st }}$ ed Vienna, Austria: Wilhelm Braumüller; 1881.

2. Goldenhar M. Associated malformations of the eye and ear, particularly the epibulbar dermoid syndrome, accessory auricle and fistula auris congenital, and their relation to mandibulofacial dysostosis [in French]. J Génét Hum. 1952;1:243-282.

3. Gorlin RJ, Jue KL, Jacobsen U, Goldschmidt E. Oculoauriculovertebral dysplasia. J Pediatr. 1963;63:991-999.

4. Converse JM, Coccaro PJ, Becker M, Wood-Smith D. On hemifacial microsomia. The first and second branchial arch syndrome. Plast Reconstr Surg. 1973;51(3):268-279.

5. Grabb WC. The first and second branchial arch syndrome. Plast Reconstr Surg. 1965;36(5):485-508.

6. Gorlin RJ, Cohen MM, Hennekam RCM. Syndromes of the Head and Neck. $4^{\text {th }}$ ed. New York, NY: Oxford University Press; 2001.

7. van Bever Y, van den Ende JJ, Richieri-Costa A. Oculo-auriculo-vertebral complex and uncommon associated anomalies: Report on 8 unrelated Brazilian patients. Am J Med Genet.1992;44(5):683-690.

8. Vendramini S, Richieri-Costa A, Guion-Almeida ML. Oculoauriculovertebral spectrum with radial defects: A new syndrome or an extension of the oculoauriculovertebral spectrum? Report of fourteen Brazilian cases and review of the literature. Europ J Hum Genet. 2007;15(4):411-421.

9. Kokavec R. Goldenhar syndrome with various clinical manifestations. Cleft Palate Craniofac J. 2006;43(5):628-634.

10. Lam CH. A theory on the embryogenesis of oculo-auriculo-vertebral (Goldenhar syndrome). J Craniofac Surg. 2000;11(6):547-552.

11. Hartsfield JK. Review of the etiologic heterogeneity of the oculoauriculo-vertebral spectrum (hemifacial microsomia). Orthod Craniofac Res. 2007;10(3):121-128.

12. Caccamese JF Jr, Costello BJ, Mooney MP. Novel deformity of the mandible in oculo-auriculo-vertebral spectrum: Case report and literature review. J Oral Maxillofac Surg. 2006;64(8):1278-1282.

13. Sinha S, Singh AK, Mehra A, Singh R. Goldenhar syndrome - a literature review. JSM Dent. 2015;3(1):1052.
14. Lakshman AR, Subhas BG, Castelino RL, Kalkur C, Halimet N. Goldenhar syndrome: A case report with review of literature. MOJ Biol Med. 2017;1(1):18-20.

15. Bhuyan R, Pati AR, Bhuyan SK, Nayak BB. Goldenhar syndrome: A rare case report. J Oral Maxillofac Pathol. 2016;20(2):328.

16. Saxena R, David MP. Goldenhar syndrome - a rare case report. $J$ Genet Syndr Gene Ther. 2012; 3(2):1-4.

17. Mellor DH, Richardson JE, Douglas DM. Goldenhar's syndrome. Oculoauriculo-vertebral dysplasia. Arch Dis Child. 1973;48(7):537-541.

18. Vinay C, Reddy RS, Uloopi KS, Madhuri V, Sekhar RC. Craniofacial features in Goldenhar syndrome. J Indian Soc Pedod Prev Dent. 2009;27(2):121-124.

19. Patil NA, Patil AB. Goldenhar syndrome: Case report. IJSS J Surg. 2015;1(1):18-19.

20. Weerda H. Ear Auricle Surgery. Injuries, Defects and Anomalies [in German]. Stuttgart, Germany: Thieme; 2004:105-226.

21. Subramaniam P, Girish Babu KL, Jayasurya S, Prahalad D. Dental management of a child with Goldenhar syndrome. Europ J Gen Dent. 2014;3(2):158-162. 